\title{
Preliminary Phytochemical Content and Antidiabetic Potential Investigations of Panda oleosa (Pierre) Used in Kisangani Areas
}

\author{
Frédéric Katemo Muhoya1, Justin Ntokamunda Kadima², Njakarinala Ranarivelo ${ }^{3,4}$, \\ Michel Frédérich ${ }^{3}$, Philippe Hubert ${ }^{5}$, Roland Marini Djang'eing'a1,5*

\footnotetext{
${ }^{1}$ Department of Pharmacy, Faculty of Medicine and Pharmacy, University of Kisangani, Kisangani, Democratic Republic of Congo ${ }^{2}$ School of Medicine and Pharmacy, University of Rwanda, Huye, Rwanda

${ }^{3}$ Laboratory of Pharmacognosy, CIRM, Department of Pharmacy, University of Liege (ULg), Liège, Belgium

${ }^{4}$ Centre National d'Application des Recherches Pharmaceutiques (CNARP), Ecole Doctorale en Génie des Procédés et des Systèmes Industriels, Agricoles et Alimentaires (GPSIAA), University of Antananarivo, Antananarivo, Madagascar ${ }^{5}$ Laboratory of Analytical Chemistry, CIRM, Department of Pharmacy, University of Liege (ULg), Liège, Belgium

Email: *djangeinga@gmail.com
}

How to cite this paper: Muhoya, F.K., Kadima, J.N., Ranarivelo, N., Frédérich, M., Hubert, P. and Djang'eing'a, R.M. (2017) Preliminary Phytochemical Content and Antidiabetic Potential Investigations of Panda oleosa (Pierre) Used in Kisangani Areas. American Journal of Analytical Chemistry, 8, 564-581.

https://doi.org/10.4236/ajac.2017.89041

Received: July 18, 2017

Accepted: September 8, 2017

Published: September 11, 2017

Copyright (c) 2017 by authors and Scientific Research Publishing Inc. This work is licensed under the Creative Commons Attribution International License (CC BY 4.0).

http://creativecommons.org/licenses/by/4.0/ c) (i) Open Access

\begin{abstract}
Panda oleosa Pierre (POP), a tropical plant tree, has been used in traditional medicine in Kisangani city and around to treat various diseases including diabetes and HIV/AIDs. This study aims to evaluate the chemical composition of POP extracts while setting up chromatographic fingerprints for their quality control, and the anti-hyperglycemic potential of trunk bark aqueous extracts of POP. Common chemical reactions were used for identification of main secondary metabolic groups. Thin layer chromatography was used to set up several chromatographic fingerprints of water and alcoholic extracts while evaluating chemical composition. Oral glucose tolerance test served to induce hyperglycemia in a rabbit model. The extracts were given as $25 \mathrm{mg} / \mathrm{kg}, 50$ $\mathrm{mg} / \mathrm{kg}$, and $100 \mathrm{mg} / \mathrm{kg}$ body weight, 30 minutes before loading animals with glucose $4 \mathrm{~g} / \mathrm{kg}$. Blood samples were collected at various times: just before extracts (T-30), before (T0) and after glucose load (T30, T60, T120, and T180). Blood glucose levels were measured with One Touch Glucometer. The identification tests revealed the presence of saponins (3.58\%), tannins (5\%); alkaloids, quinones, flavonoids, and terpenes sterols could not be formerly detected by the reagents used. Interesting chromatographic spots were observed whose behaviors are of catechic tannin proanthocyanes. The extract significantly reduced glucose levels in dose dependent manner as compared to control and glibenclamide reference groups. The average of mean percentage of reduction in glucose level at T120 with the extract $100 \mathrm{mg} / \mathrm{kg}$ was close to that of
\end{abstract}


glibenclamide $0.25 \mathrm{mg} / \mathrm{kg}$ ( $49 \%$ and $40.2 \%$ ). These findings back the traditional use of the plant to treat diabetic patients and constitute a foundation for an extensive study to find a new antidiabetic phythomedicine.

\section{Keywords}

Panda oleosa, Forest Tree, Phytochemical, Thin Layer Chromatography, Phythomedicine, Antidiabetic Effect, Rabbit

\section{Introduction}

Diabetes is a complex disease both by its pathophysiological mechanisms, its genetic determinism as well as the genesis of its complications [1] (Morgan, 2012). It is a metabolic disease characterized by chronic hyperglycemia due to a defect in insulin secretion or action, or both [1]. In addition to the acute complications of ketoacidosis, hyperosmolar syndrome, chronic hyperglycaemia degenerates into more or less severe complications [2] [3]. The disease first developed in rich countries in relation to the aging phenomenon, physical inactivity and obesity, but its spread is also felt in poor countries because of a genetic predisposition associated with infections and lifestyle changes such as rapid urbanization, sedentarisation, food habits, malnutrition [4]. According to the WHO $1^{\text {st }}$ World Diabetes Report [5], 422 million people worldwide have diabetes, and more than $80 \%$ of diabetes deaths occur in low- and middle-income countries. Diabetes could become the $7^{\text {th }}$ leading cause of death worldwide by 2030 . The Democratic Republic of the Congo (DRC) is not spared by this epidemiological surge [6] with nearly one million diabetics, $5 \%$ to $10 \%$ of whom are children and adolescents. Managing diabetic patients requires non-pharmacological and pharmacological therapies for life [7]. Modern pharmacological drugs that are affordable in rich-countries are however out of reach for many populations living in resources-limited countries. Poor countries are thus encouraged to evaluate alternative strategies based mainly on the use of traditional herbal therapies. The WHO 2014 strategy aims at supporting Member States in developing proactive policies and implementing action plans that will strengthen the role traditional medicine plays in keeping populations healthy [8] [9]. Nowadays, a thousand plants have been screened worldwide to explore the antidiabetic potential with the objective of integrating them into the modern conventional herbalism. For example, Mohd et al. found [10] that the ethnic communities of Thoubal district in Manipur (India) use various plants from which 54 are indicated for treating diabetes. Prasad et al. [11] tested the aqueous extract of leaves of Murraya koenigii, Psidium guajava and Catharanthus roseus, for their claimed antidiabetic activity against streptozotocin induced diabetic albino rats. At the dose of $500 \mathrm{mg} / \mathrm{kg}$ body weight, significant beneficial effects were reported in various physiological/histological parameters altered during diabetic 
manifestations and these effects are quite comparable with glibenclamide.

In Central Africa Region, a number of trees, shrubs, and edible herbs have been used for decades and are still used in remote areas where conventional modern antidiabetic drugs are whether unavailable or very costly [12] [13] [14]. Adebayo et al. [15] reported an ethnobotanical survey in five districts of Lagos State of Nigeria reputed for the treatment of diabetes. He found that fifty multi-component herbal recipes covered in the survey were mainly liquid preparations often administered without serious side effects. The most cited plants included Vernonia amygdalina DEL (VA), Bidens pilosa, Carica papaya, Citrus aurantiifolia, Ocimum gratissimum, Momordica charantia and Morinda lucida. VA supplemented diet was evaluated by Item et al. [16] for the anti-obesity, and found that plant diet also exerted hepato-protection via lowering serum alanine amino transaminase $(41.35 \%$ and $27.13 \%)$ and aspartate amino transaminase $(17.09 \%$ and $43.21 \%)$ activities $(\mathrm{P}<0.05)$. Khang et al. [17] investigated and confirmed the hypoglycemic properties of Vernonia amygdalina and its possible mechanisms of action in a single-dose streptozotocin induced diabetic rat model that might most probably be through increasing glucose transporter 4 translocation and inhibiting hepatic glucose-6-phosphatase. Adaobi et al. [18] demonstrated from their results the potentials of the leaves of Cajanus cajan as anti-diabetic therapy, which may be attributed to hypoglycemic activity and an improvement of post prandial hyperglycemia in diabetes mellitus. From a previous ethno pharmacological survey conducted in Kisangani [19], around twenty plants were inventoried as antidiabetic potentials, among which Panda oleosa Pierre. Panda (syn. Porphyranthus zenkeri Engl. or Sorindeia rubiflora Engl.) is a slow-growing plant species of the family Pandaceae native to Western and Central Africa (D.R. Congo, Congo-Brazzaville, Gabon, Central African Republic, Liberia, Ghana, Guinea, Ivory Coast, Nigeria, and Cameroon) [20]. It is an evergreen tree with a dense crown, usually growing from 10 - 20 meters tall but with some specimens to 35 meters (Figure 1).

The brownish yellow to pinkish red wood is moderately hard, and it has an irregular grain and fine texture; it is used for carpentry and making canoes [21]. Many trees produce fruits each year and fruits may persist on the tree for several months. Studies by others indicated that the tree is harvested from the wild for local use as a food, medicine and source of timber [22] [23]. The hypothesis formulated by conducting this study is that some plants and particularly Panda oleosa used in RDC traditional medicine against diabetes are actually invested with the antidiabetic properties inherent to the bioactive substances they may contain. No study has verified this use as claimed by traditional healers.

Thus the present study aims to evaluate the chemical composition and anti-hyperglycemic potential of the trunk bark aqueous extracts from a species native to DRC. The developed chromatographic fingerprints are also presented. 


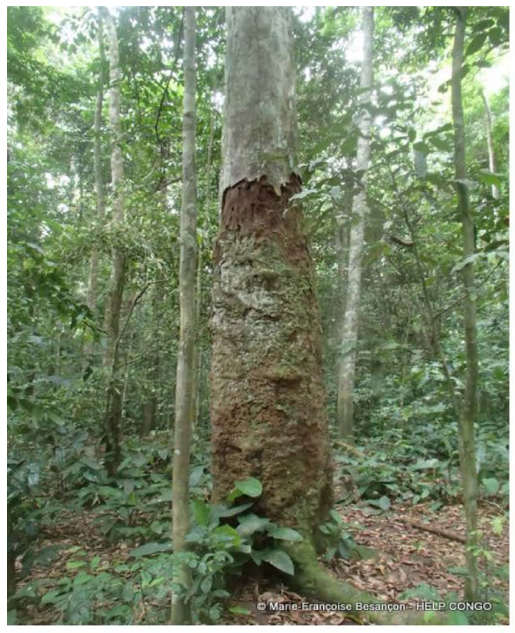

Panda oleosa trunk
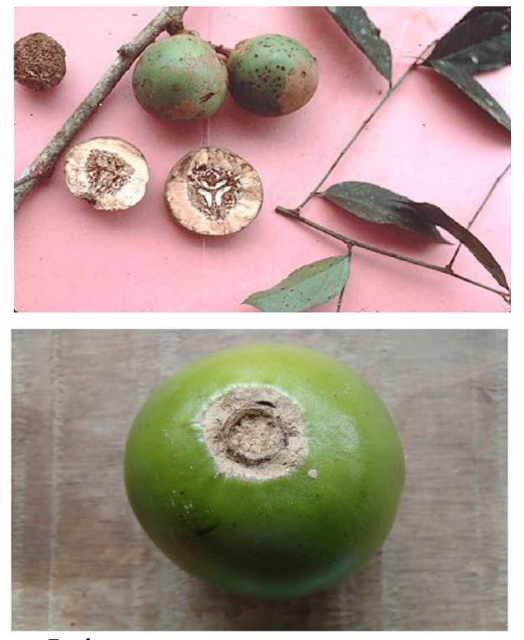

Fruit

Figure 1. Panda oleosa in Masako reserve forest $14 \mathrm{~km}$ from the city of Kisangani.

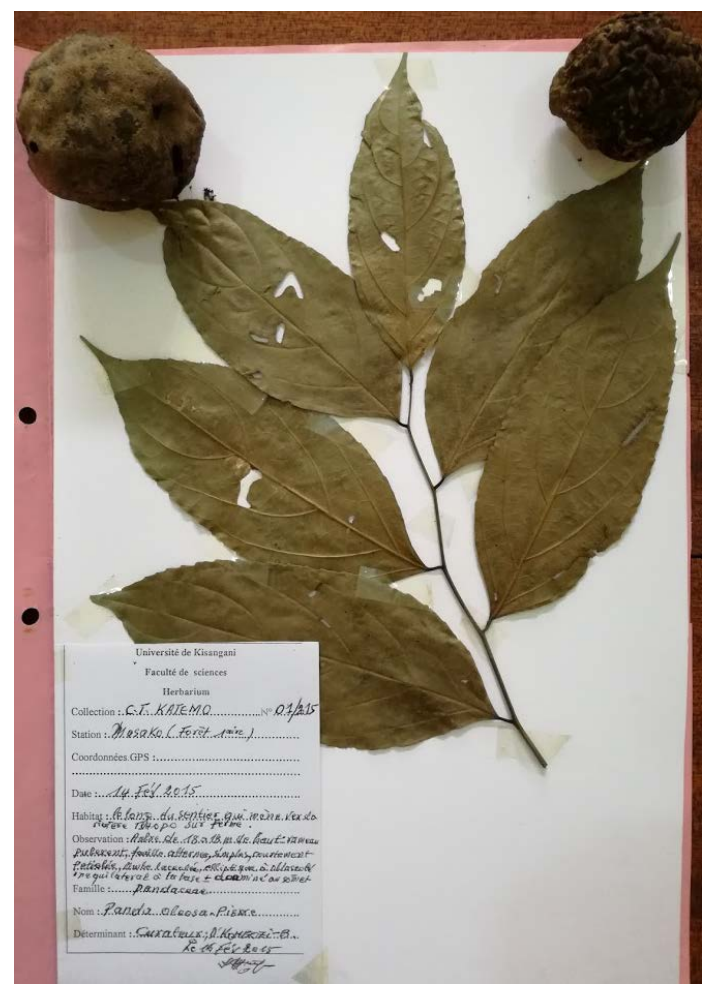

Figure 2. Panda oleosa herbarium deposed at both herbarium of the Faculty of Sciences in the University of Kisangani (Kisangani, DRC) and Meise Botanic Garden (Meise, Belgium).

\section{Materials and Methods}

\subsection{Collection of Plant Trunk Barks}

The part used is the trunk bark. Fresh barks were harvested in Masako reserve forest, $14 \mathrm{~km}$ from the city of Kisangani. Harvesting of samples was carried out in the morning from 7:00 to 9:00. The fresh barks were ground and sieved (see Figure 2). 
Specimens were authenticated in the herbarium of the Faculty of Sciences in the University of Kisangani (UNIKIS) under the number 21,243 and at a specimen was deposed to the Botanic Garden Meise (Meise, Belgium) where the identification of the same specimens was confirmed and also identified in other local vernacular names around Kisangani city namely Okale or Bokale (Turumbu tribe), Boteko (Kundu or Mongo Kundu tribe).

\subsection{Chemicals, Solvents and Reagents}

1-Butanol GR for analysis, Nitric acid 65\% GR for analysis, Vanillin for synthesis, Rutin and the TLC chromatogram plates of Silica gel 60 F254 on Plastic sheets for Analytical Chromatography were obtained from Merck (Darmstadt, Germany). Diethylether, ethylacetate and methanol for liquid chromatography grade were purchased from VWR International in Leuven (Belgium) or Fontenay-sous-Bois (France). Catechin, Epigallocatechin and Hyperoside were purchased from Extrasynthèse (Genay, France), Caffeic acid from Sigma Aldrich (St. Louis, MO, USA) and Coumaric acid from Fluka (Steinheim, Germany). Purified water was produced by ultrapure Milli-Q Plus 185 (Millipore, Billerica, MA, USA).

\subsection{Identification of Phytochemical Organic Groups}

Common methods described by Bruneto [24] and Mabika [25] were used for identification.

\subsubsection{Testing for Saponins}

$5 \mathrm{~g}$ of raw powder was soaked in $50 \mathrm{~mL}$ distillated water in a beaker; $10 \mathrm{~mL}$ of the filtrate was placed in a test tube of $16 \mathrm{~mm}$ in diameter and $160 \mathrm{~mm}$ in height and stirred. Foaming which persisted on warming for 10 minutes was taken as an evidence for the presence of saponins.

\subsubsection{Testing for Tannins and Phenolics}

$0.5 \mathrm{~g}$ of the powder was stirred with $10 \mathrm{~mL}$ of distilled water and then filtered. A few drops of $1 \% \mathrm{FeCl}_{3}$ reagent was added to the filtrate. Blue-black or blue-green coloration or precipitation was taken as an indication of the presence of phenolics and tannins.

\subsubsection{Testing for Alkaloids}

$1 \mathrm{~g}$ of the powder was soaked in $10 \mathrm{~mL}$ of $5 \% \mathrm{HCl}$ for 24 hours. The solution obtained was filtered and $3 \mathrm{~mL}$ of the filtrate was treated with a few drops of Dragendorff-Mayer's reagents. The turbidity or orange precipitate of the filtrate on addition of the reagent was taken as evidence of the presence of alkaloids.

\subsubsection{Detection of Quinones}

$5 \mathrm{~g}$ of the powder was wetted with a few drops of $\mathrm{HCl} 1 / 5 \mathrm{~N}$ and then soaked in $30 \mathrm{~mL}$ of ether-chloroform mixture $(1: 1, \mathrm{v} / \mathrm{v})$ for 24 hours in a conical flask. Then, $2 \mathrm{~mL}$ of the filtrate was mixed with the same volume of $\mathrm{NaOH} 1 / 10 \mathrm{~N}$. 
Red to purple coloration was taken as an indication of the presence of quinones.

\subsubsection{Detection of Flavonoids}

$5 \mathrm{~g}$ of the powder was heated with $50 \mathrm{~mL}$ of distillated water for 30 minutes in a hot bath. After cooling and filtration, $5 \mathrm{~mL}$ of the filtrate was mixed with $5 \mathrm{~mL}$ of ethyl alcohol 95\%, $2 \mathrm{~g}$ of magnesium turnings, and a few drops of isoamyl alcohol. The appearance of a pink, red or orange color in the isoamyl alcohol supernatant layer indicates the presence of flavonoids.

\subsubsection{Detection of Sterols and Terpenes}

$1 \mathrm{~g}$ of plant material, coarsely crushed, was macerated for 24 hours in $20 \mathrm{~mL}$ of ether. About 5 drops of the macerate is evaporated on a watch glass. The residue is mixed with 2 drops of acetic anhydride. The addition of a drop of $32 \%$ sulfuric acid turns the solution to mauve-green coloration in the presence of sterols and terpenes.

\subsection{Quantification of Saponins, Tannins and Mineral Ashes}

\subsubsection{Determination of Polyphenols [26]}

$100 \mathrm{~g}$ of the plant powder was heated to boiling in $700 \mathrm{~mL}$ of distilled water for 30 minutes. The decoction obtained after filtration on Whatman No. 3 is placed in a funnel. After addition of one-third of its volume with n-butanol, the mixture is stirred vigorously, and then rested for an hour. The n-butanol upper layer containing polyphenols is set aside. The aqueous lower layer is treated 4 times as above. The n-butanol phases are combined and filtered through anhydrous sodium sulfate. The filtrate is evaporated in an oven at $100^{\circ} \mathrm{C}$ up to constant weight. The weight of the residue is expressed as the percentage $\mathrm{w} / \mathrm{w}$ of tannins or flavonoids if they are present, or both in $100 \mathrm{~g}$ of plant dry material.

\subsubsection{Dosage of Saponins [27]}

$100 \mathrm{~g}$ of powder of plant material was refluxed with $300 \mathrm{~mL}$ of $96 \%$ ethanol for 2 hours. The operation is repeated until the clarification of the solvent. The various extracts are combined, filtered and concentrated in vacuum to a small volume. Saponins are repeatedly precipitated by addition of diethyl ether. The solvent was removed by decantation and the precipitate is re-dissolved in $96 \%$ ethanol, then treated with activated charcoal and heated at reflux until boiling. The solution is then filtered through cotton wool. The filter is washed several times with ethanol until complete clarification. The ethanol solution is concentrated again to a small volume and the saponins precipitated by adding an equal volume of diethyl ether. The precipitate is separated by decantation and then dried in an oven to constant weight. The weight of the residue is expressed as the percentage $\mathrm{w} / \mathrm{w}$ of tannins flavonoids if they are present, in $100 \mathrm{~g}$ of plant dry material.

\subsection{Quantification of Water Content and Mineral Ashes}

\subsubsection{Determination of Water Content and Volatile Matter [28]}

Fresh material of known weight is dried in an oven at $105^{\circ} \mathrm{C}$ to constant weight. 
The moisture is deduced by weighing the difference between the fresh weight and dry matter.

\subsubsection{Determination of Crude Mineral Ash Content [28] [29]}

The test sample of known weight is heated in an electric furnace $550^{\circ} \mathrm{C}$ until its complete ignition.

The ash obtained by ignition is dissolved with boiling water or $\mathrm{HCl} 20 \%$ solution. After filtration, the amount of ash retained on the filter is weighted and expressed in percentage.

\subsection{Quantification of Water Content and Mineral Ashes}

The fresh barks were finely ground. An aliquot of $20 \mathrm{~g}$ was soaked in $80 \mathrm{~mL}$ of distilled water in a clean beaker. The mixture was boiled for 15 minutes paying attention to occasionally add a small amount of distilled water to compensate for water loss through evaporation. After cooling, the mixture was filtered on Whatman filter $\mathrm{N}^{\circ} 3$ and further evaporated to dryness. The dry residue was reconstituted in solution with distillated water to a known concentration.

\subsection{Chromatographic Fingerprints}

Several thin layer chromatographic systems were tested for the establishment of fingerprinting. These concerned mainly the catechol tannin derivatives.

\subsubsection{Extraction}

In order to highlight the presence of catechol derivatives in the Panda oleosa plant, a powder was obtained from the trunks of Panda oleosa (Pandaceae). From this vegetal material, three extraction processes were applied to obtain extract samples:

1) Water extraction at hot temperature by mean of reflux.

It is an aqueous decoction. The plant material $(1 \mathrm{~g})$ is placed with $10 \mathrm{~mL}$ of deionized water in a refluxing water bath. The mixture is brought to $110^{\circ} \mathrm{C}$ for $15 \mathrm{~min}$. The solution is filtered and then evaporated to dryness. The extract is recovered with $1 \mathrm{~mL}$ of methanol. This is coded extract No. 1 .

2) Extraction in cold alcoholic medium

It is an alcoholic maceration with stirring. The Panda oleosa powder $(1 \mathrm{~g})$ is placed in an Erlenmeyer flask with $10 \mathrm{~mL}$ of methanol. The mixture is placed under magnetic stirring for $70 \mathrm{~min}$. The macerate obtained is filtered and evaporated to dryness. The extract is recovered with $1 \mathrm{~mL}$ of methanol. This is coded extract No. 2

3) Extraction in cold water

This is an aqueous maceration with stirring. $1 \mathrm{~g}$ of Panda oleosa powder is macerated in $10 \mathrm{~mL}$ of water and placed under magnetic stirring for $70 \mathrm{~min}$. The solution obtained is filtered and then evaporated to dryness. The product is recovered with $1 \mathrm{~mL}$ of methanol. This is extract No. 3 .

The methanol insoluble part is recovered with water. This is the coded extract 
No. 3'.

\subsubsection{Chromatographic Analyses in Thin Layer}

1) Operating conditions for aqueous and alcoholic extract

Mobile phase: Ethyl acetate/Water/Formic acid/Nitric acid (70:20:3:2; v/v/v/v).

The solvents are mixed and thoroughly stirred in a separator funnel. The upper phase of the mixture serves as the mobile phase whereas the lower phase is discarded.

\section{Reference:}

- Solution of Rutin + Hyperoside and coumaric acid + caffeic acid

- Solution of (-)-Catechin and (+)-Epigallocatechin

Spot: $30 \mu \mathrm{L}$

Revelation: After development, the chromatogram plate is observed under UV lamp at $366 \mathrm{~nm}$; then sprayed with hydrochloric vanillin solution $(1 \mathrm{~g} / 100 \mathrm{~mL})$ (Ref. French Pharmacopoeia 2016) and observed directly in the visible lamp.

The presence of catechol derivatives is marked by pink spots after revelation with hydrochloric vanillin.

2) Operating conditions for concentrated aqueous and alcoholic extract

a) Preparation of the sample:

The sample coded 1 is decanted, and the supernatant is carefully removed with a pipette and the solution evaporated. Prepare 3 concentrated extracts by performing successive extractions as following:

- Recover the dry extract with dichloromethane. The extract 1a is obtained.

Then, recover the same dry extract with a mixture of diethyl ether and ethyl acetate $(1 / 1 ; \mathrm{v} / \mathrm{v})$. The extract $1 \mathrm{~b}$ is obtained.

- Finally, rinse with methanol. This is extract $1 c$.

b) Chromatographic analysis (TLC)

Mobile phase: Ethyl acetate/Water/Formic acid/nitric acid (70:20:3:2; v/v/v/v). The solvents are mixed and thoroughly stirred in a separator funnel. The upper phase of the mixture is used as the mobile phase. The lower phase is discarded.

Reference: solution of (-)-Catechin and (+)-Epigallocatechin Spots: $80 \mu \mathrm{L} / 100 \mu \mathrm{L} / 20 \mu \mathrm{L} / 20 \mu \mathrm{L}$ for $1 \mathrm{a} / 1 \mathrm{~b} / 1 \mathrm{c} / 2$, respectively

Revelation: After development, the chromatogram is observed under UV at $366 \mathrm{~nm}$; then sprayed with hydrochloric vanillin solution $(1 \mathrm{~g} / 100 \mathrm{~mL})$ and observed directly in the visible.

The presence of catechic derivatives is marked by pink spots after revelation with hydrochloric vanillin.

\subsection{Test of Anti-Hyperglycemic Activity of Aqueous Extracts}

The anti-hyperglycemic effect was evaluated by Oral Glucose Tolerance Test (OGTT) as previously described [14]. Rabbits were used for this experiment. Their weight varied between $1.1 \mathrm{~kg}$ and $2.4 \mathrm{~kg}$ with an average weight of $1.94 \pm$ $0.68 \mathrm{Kg}$. The animals were kept in the animal boundary of the Faculty of Science for acclimatization, prepared and used according to the standards required for 
experiment on laboratory animals [30]. Animals were randomly assigned to one of the 5 groups, each group including 5 rabbits: 1) negative control untreated group (Control); 2) reference control group given glibenclamide $0.25 \mathrm{mg} / \mathrm{kg}$ (Gliben); 3) test group given decoction $25 \mathrm{mg} / \mathrm{kg}$ (Ex25); 4) test group given decoction $50 \mathrm{mg} / \mathrm{kg}$ (Ex 50); 5) test group given decoction $100 \mathrm{mg} / \mathrm{kg}$ (Ex100). The extracts were given 30 minutes before loading animals with glucose $4 \mathrm{~g} / \mathrm{kg}$. Blood samples were collected at various times: just before extracts ( $\mathrm{T}-30$ ), before glucose (T0) and after glucose (T30, T60, T120, and T180). Blood glucose levels were measured with One Touch Glucometer (Accu-Chek ${ }^{\circledR}$ ). Pharmacological test results are obtained for each animal per group. All animals were fasted fourteen hours before experiment to enable stable baselines of glucose levels and avoid food interference on the absorption of the plant extracts.

\subsection{Data Analysis}

Mean glucose levels (MGLs) in blood samples were calculated for each group of 4 animals at different times. Mean percentages of reduction (MPRs) in glucose levels from control values were also calculated at each time. Windows Excel Statistic tool (ANOVAs) was used to detect differences between different groups at $\mathrm{p}<0.05$ significance level.

\section{Results}

\subsection{Phytochemical Composition}

The Identification tests revealed the presence of saponins (3.58\%) and tannins (5\%) in the trunk bark decoction. Alkaloids, quinones, flavonoids, and terpenes sterols could not be detected by the reagents used (Table 1). Water content accounted for $86.1 \%$ of fresh bark; mineral ashes were $16.8 \%$ for water insoluble, $32.3 \%$ for water soluble ashes and $66 \%$ for $\mathrm{HCl} 20 \%$ soluble ashes.

Table 1. Phytochemical content of Panda oleosa bark.

\begin{tabular}{lc}
\hline Components & Bark content $(\%, w / w)$ \\
\hline Saponins & $3.6 \pm 0.5$ \\
Tannins & $5.0 \pm 0.5$ \\
Alkaloids & \pm \\
Flavonoids & - \\
Quinones & - \\
Terpenes sterols & $86.1 \pm 2.1$ \\
Water content & $16.8 \pm 1.0$ \\
Insoluble arches in water & $32.3 \pm 5.2$ \\
Soluble arches in water & $66.0 \pm 4.7$ \\
Soluble arches in HCl $20 \%$ & \\
\hline
\end{tabular}

Values are mean $\pm S D(n=3)$ 


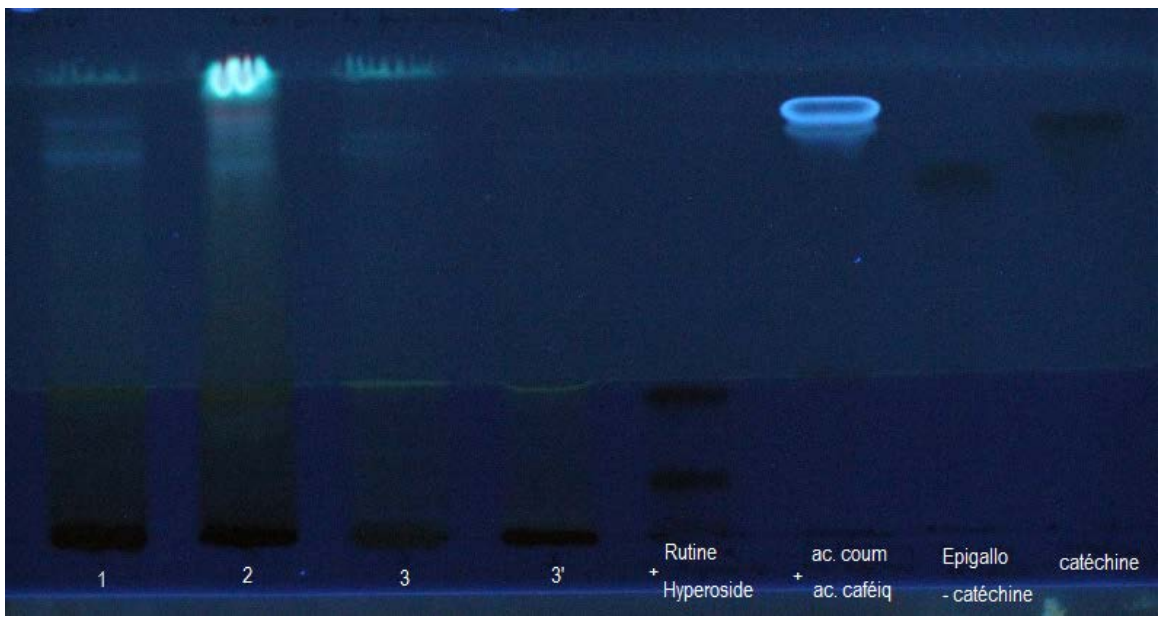

Figure 3. Thin layer chromatogram of extract observed at $366 \mathrm{~nm}$ lamp.

\subsection{Thin Layer Chromatographic Analyses}

\subsubsection{Preliminary Results of Aqueous and Alcoholic Extractions}

After a first inconclusive test, we conducted a second test. The results are given on the following chromatograms (Figure 3).

Under UV at $366 \mathrm{~nm}$, there is a low presence of caffeic acid in spot 1 and 3, and more intense in spot 2 , with clear fluorescent blue coloring. The other compounds are not disclosed nor the controls or references.

On the other hand, after revelation with vanillin, very interesting results were observed. On sample 1 (extraction by reflux heating), we can see a pink band $(\mathrm{Rf}=0.85)$. Although this is not very visible, we can argue that catechol derivatives are present in the sample, but relative to a low concentration. For sample No. 2 (extraction with methanol), there is a presence of pink-colored stains. But its migration leaves a trail. This may be due to a high concentration of the deposit, thus, we can not clearly distinguish the spots. However, this suggests presence of catechic tannins that interact with silica. We also observed a stagnant band that has not migrated ( $R f=0)$, suggesting presence of very polar proanthocyanins. The same applies to samples 2, 3 and 3 '.

For the other two samples 3 and 3', there was no clearly visible spot in the upper part of the chromatogram. The aqueous maceration does not appear to be suitable for extracting the catechin derivatives of $P$. oleosa.

\subsubsection{Results of Concentrated Alcoholic Extracts}

The thin layer chromatograms of the different extracts are presented at Figures 4-7.

\subsection{Anti-Hyperglycemic Activity}

The evolution of mean glucose levels (MGLs) at different measurement times for the tested groups is shown in Figure 8. The normal physiological values measured before treatment varied from $72 \mathrm{mg} / \mathrm{dL}$ to $109 \mathrm{mg} / \mathrm{dL}$. After administration of the extracts and glucose loading, the blood glucose rose above $300 \mathrm{mg} / \mathrm{dL}$ in 


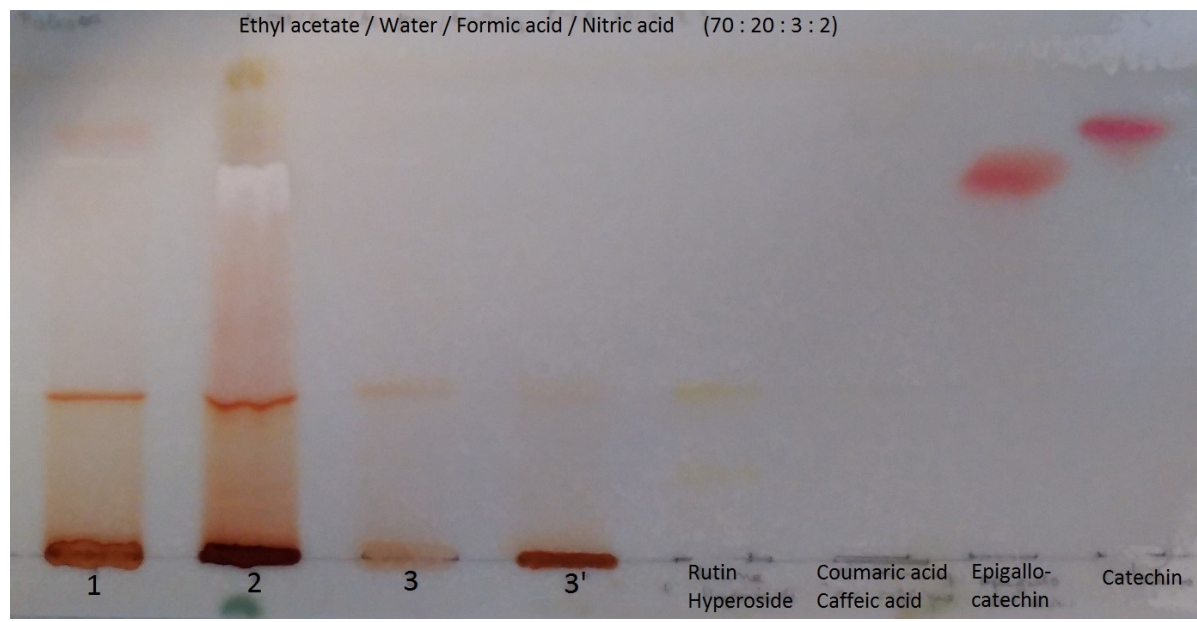

Figure 4. Thin layer chromatogram extracts observed at the visible after revealing with chlorhydric vaniline.

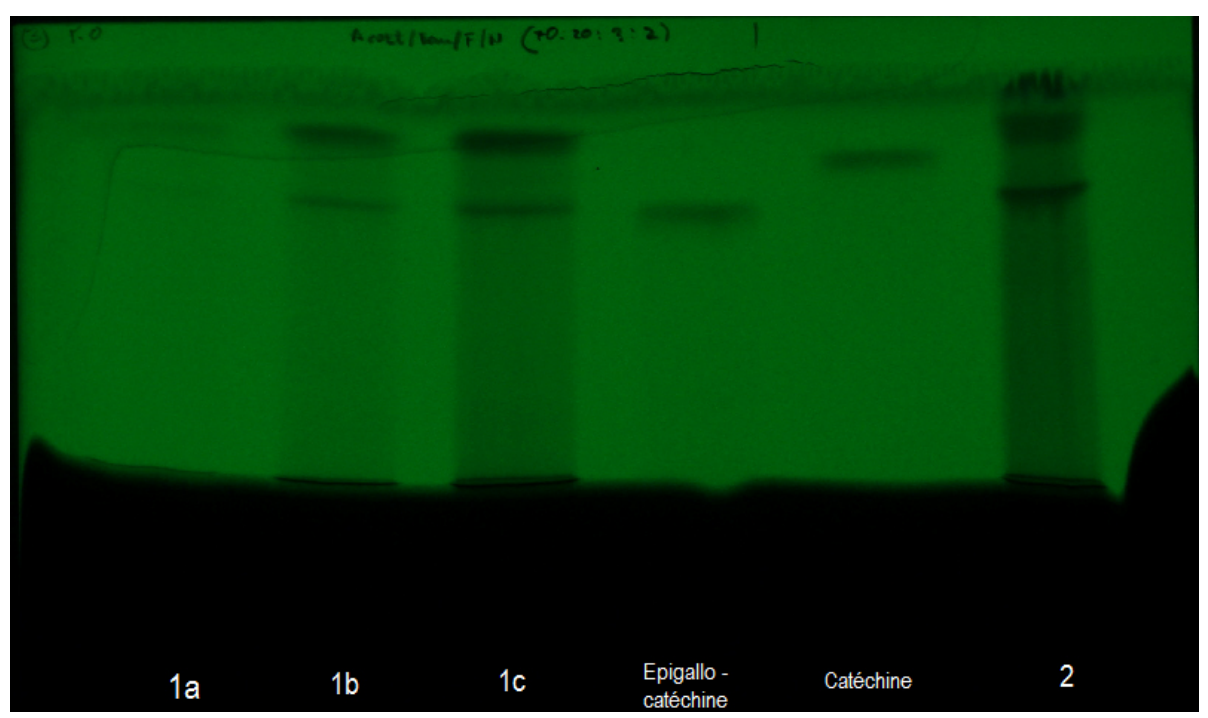

Figure 5. Chromatogram of extracts observed under UV lamp at $254 \mathrm{~nm}$.

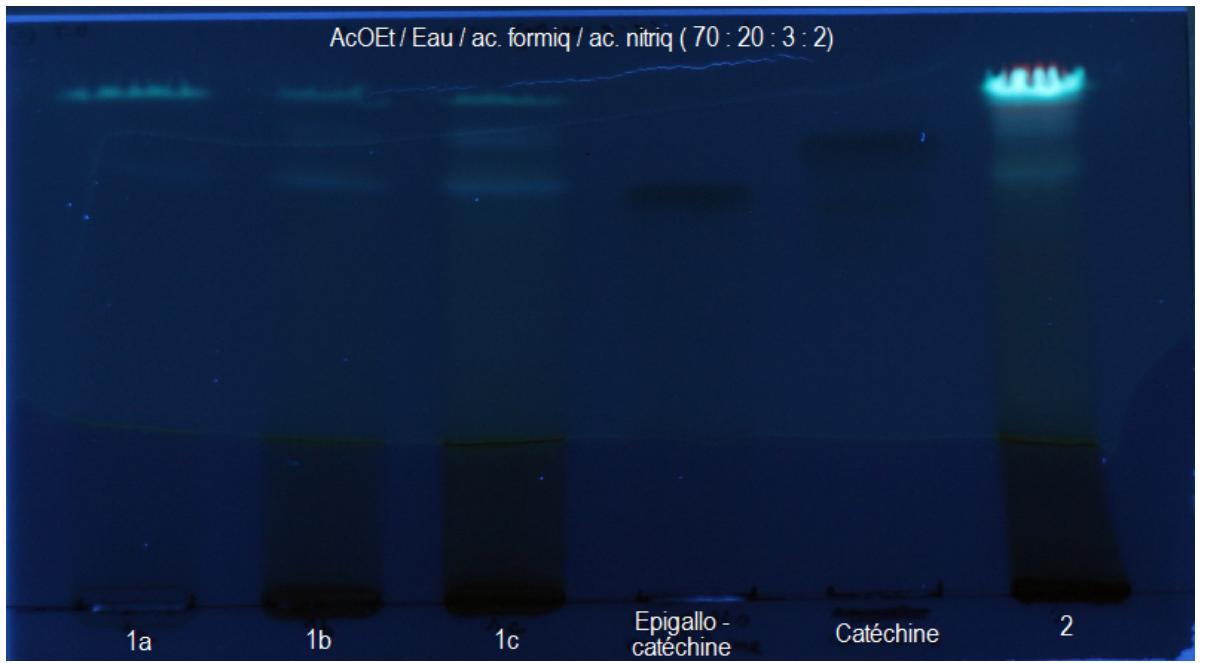

Figure 6. Chromatogram of extracts observed under UV lamp at $366 \mathrm{~nm}$. 


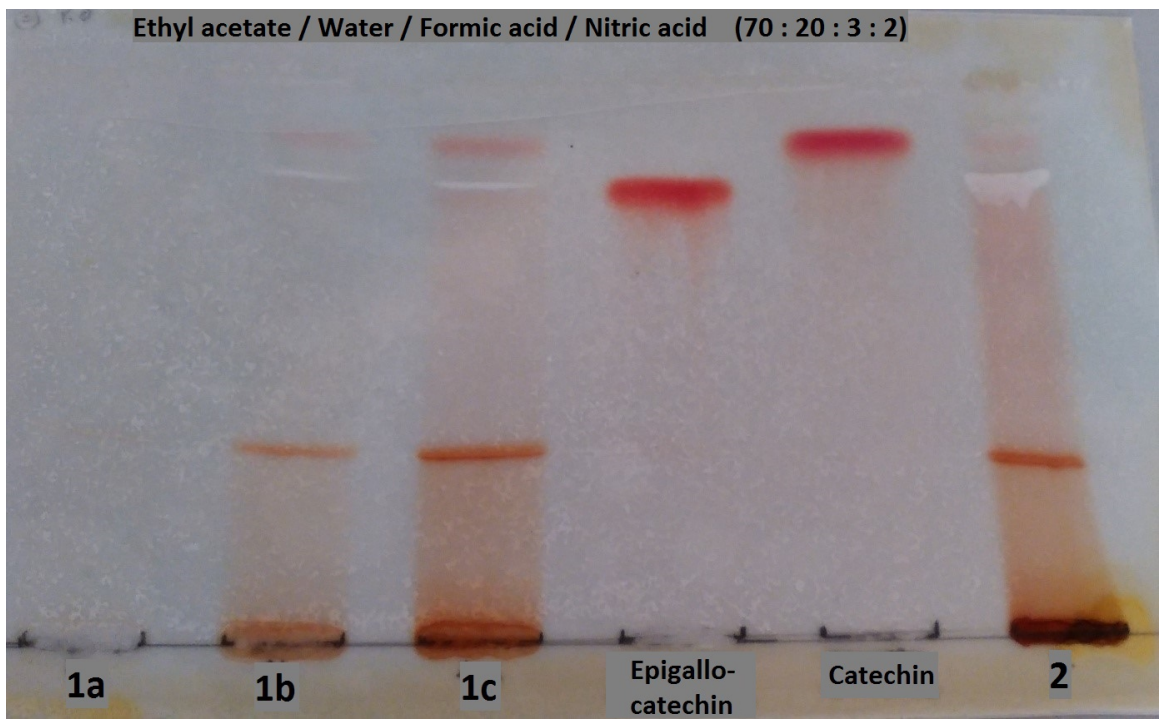

Figure 7. Chromatogram of extracts observed in the visible after revelation with chlorhydric vanillin.

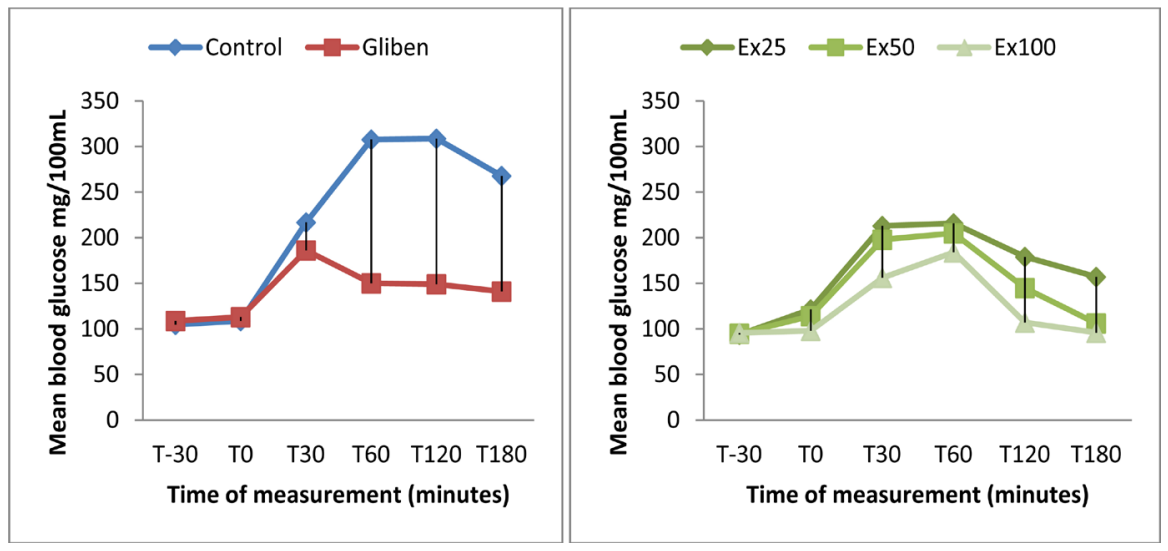

Figure 8. Mean blood glucose levels ( $\mathrm{n}=5$ rabbits per group and per time point) observed during 180 minutes in rabbits treated with Panda oleosa extract. Control (untreated hyperglycemic rabbits); Gliben (reference glibenclamide $0.25 \mathrm{mg} / \mathrm{kg}$ ); Ex25 (Extract 25 $\mathrm{mg} / \mathrm{kg}$ ); Ex50 (Extract 50 mg/Kg); Ex100 (Extract 100 mg/Kg).

control untreated animals after 60 minutes and then decreased to $268 \mathrm{mg} / \mathrm{dL}$, still above the normal baseline values. In animals treated with the plant extracts, blood glucose levels also rose and decreased in dose-dependent manner.

Table 2 shows the activity in terms of percentage of reduction in glucose levels from the control untreated group values. The efficacy of glibenclamide $(0.25$ $\mathrm{mg} / \mathrm{kg}$ as reference) at T120 is close to that of the extract $50 \mathrm{mg} / \mathrm{kg}$, greater than $25 \mathrm{mg} / \mathrm{kg}$ and less than $100 \mathrm{mg} / \mathrm{kg}$. The values are significantly different between groups $(\mathrm{p}<0.004)$.

\section{Discussion}

The phytochemical screening done in the current study revealed the presence of saponins (3.6\%) and tannins (5\%) in the trunk bark decoctions while alkaloids, 
Table 2. Mean percentages of reduction (MPRs) in glucose levels from control group values ( $\mathrm{n}=5$ rabbits per time point and treatments) at measurement times.

\begin{tabular}{lccccc}
\hline Treatments & T30 & T60 & T120 & T180 & AMPC \\
\hline Glibenclamide 0.25mg/kg & $13.1 \pm 0.9$ & $51.3 \pm 3.3$ & $51.8 \pm 1.0$ & $47.4 \pm 0.8$ & 40.9 \\
Extract $25 \mathrm{mg} / \mathrm{kg}$ & $0.5 \pm 1.6$ & $29.8 \pm 6.5$ & $42.1 \pm 4.2$ & $41.4 \pm 11.6$ & 28.5 \\
Extract $50 \mathrm{mg} / \mathrm{kg}$ & $7.5 \pm 8.4$ & $30.8 \pm 6.2$ & $53.1 \pm 4.9$ & $60.4 \pm 6.7$ & 38.0 \\
Extract $100 \mathrm{mg} / \mathrm{kg}$ & $27.1 \pm 4.7$ & $40.2 \pm 5.5$ & $65.4 \pm 6.8$ & $64.2 \pm 5.6$ & 49.2 \\
Extract $200 \mathrm{mg} / \mathrm{kg}$ & $72.0 \pm 1.7$ & $80.5 \pm 2.9$ & $84.5 \pm 2.7$ & $82.1 \pm 1.8$ & 79.8 \\
\hline
\end{tabular}

$\mathrm{MPR}=100$ (Control glucose level-Extract glucose level)/Control glucose level); Average = mean $($ MPRT30 to MPRT180).

quinines, flavonoids, and terpenes sterols could not formally be detected with the reagents used. Phytochemical studies by others also showed that the seeds of Panda oleosa fruit contain about $50 \%$ of oil on a dry matter basis composed of myristic acid $1 \%$, palmitic acid $26 \%$, stearic acid $6 \%$, arachidic acid $0.5 \%$, oleic acid $33.5 \%$ and linoleic acid.

At the UV lamp under $254 \mathrm{~nm}$, we did not find any specific revelation except for the black bands in the extracts $1 \mathrm{~b}, 1 \mathrm{C}$ and 2, corresponding to the Rf of catechin and epigallo-catechin.

At UV under $366 \mathrm{~nm}$, a clear blue fluorescence is observed at extracts 1a, 1b, and several low strips at extract 1c.

On the other hand, the revelation with the vanilla gives several interesting information. We could distinguish samples $1 \mathrm{~b}, 1 \mathrm{c}$ and 2 from pink spots at $\mathrm{Rf} \approx$ 0.85 . And even if the extract $1 \mathrm{c}$ has a small trail, we can see a pink strip at an $\mathrm{Rf}$ around 0.73 . The orange bands that lie on the spot line and in $\mathrm{Rf}=0.3$ may also correspond to other types of catechetical derivatives. The observed trails may due to interactions with the stationary phase and suggest the presence of di- and trimeric compounds of 4-O-methylgallocatechin [31]. On the other hand, we find that there is no visible band on the extract 1a. The presence of these pink and orange spots demonstrates the existence of catechic derivatives in these extracts and confirms the presence of these very interesting compounds in the trunk bark of $P$. oleosa. In particular, there are compounds similar to proanthocyan, which is found in cinnamon (Cinnamomum zeylanicum), widely used in the food industry and for the treatment and prevention of diseases such as diabetes [32] [33], as well by animals of equatorial forest [34].

Furthermore, the trunk bark extract of Panda oleosa exhibited HIV-inhibitory activity, and the authors related the anti-HIV activity to 4 '- $O$-methylgallocatechin [35] [36].

No study has been reported in the literature about the antidiabetic activity of Panda oleosa but ethnopharmacological claims. The result of this study has demonstrated the antidiabetic potential of the trunk bark extract. The OGTT elevated blood glucose levels over normal values. The rates of reduction in blood glucose after glucose loading to animals treated with plant extracts and reference 
glibenclamide were significantly different $(\mathrm{p}<0.05)$. The efficacy of glibenclamide $(0.25 \mathrm{mg} / \mathrm{kg}$ as reference) at T120 is close to that of the extract $50 \mathrm{mg} / \mathrm{kg}$, greater than $25 \mathrm{mg} / \mathrm{kg}$ and less than $100 \mathrm{mg} / \mathrm{kg}$. However, the percentage of reduction by glibenclamide at T60 is greater than that of the extract $100 \mathrm{mg} / \mathrm{kg}$, meaning an earlier onset of action for glibenclamide.

Not withdrawing the action of saponins, the antidiabetic action may be related to tannins. New classes of tannins (oligomeric hydrolysable tannins, complex tannins, and other metabolites and condensates) have been isolated from various medicinal plants. In general, tannins are endowed with noticeable biological and pharmacological activities (inhibition of carcinogenesis, host-mediated antitumor activity, antiviral activity, and inhibition of active oxygen, such as inhibition of lipid peroxidation and lipoxygenase, xanthine oxidase, and monoamine oxidase [31] [37] [38] [39] [40] [41]. Condensed tannins extracted from the amaranth grain or amaranth leaves, finger millet, field bean, sunflower seeds, and drumstick exerted significantly high antioxidant and antidiabetic activities [41].

According to their structure and their genin, saponins are classified into two groups, steroidic saponin and triterpenic saponin. In the present article the latter were identified using the corresponding specific chemical reaction.

The triterpene saponosides are either pentacyclic or tetracyclic [42]. The latter are often endowed with very interesting therapeutic properties with the example of the ginsenoside isolated from the ginseng root (Panax ginseng). It is both<smiles>[CH]OC(C)(CCC=C(C)C)C1CCC2(C)C1C(O)CC1C3(C)CCC(O)C(C)(C)C3C(O[GaH])CC12C</smiles>

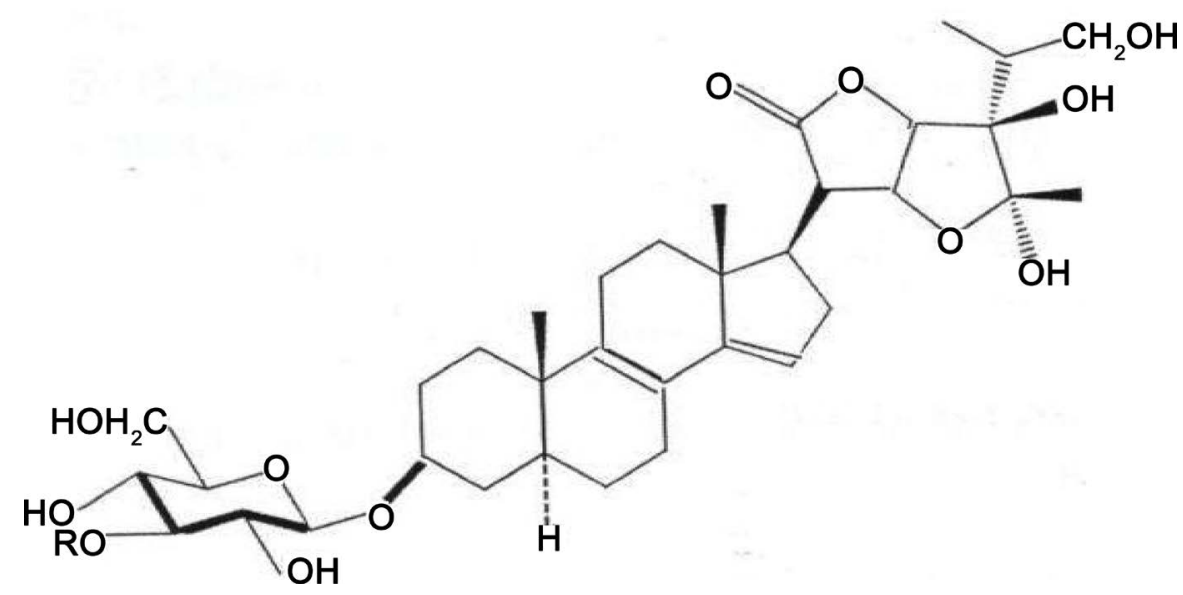

Figure 9. Structures of Ginsenoside and of Vernonioside F1 $(\mathrm{R}=\mathrm{H})$ and Vernonioside F2 $(\mathrm{R}=\beta=\mathrm{D}$-Xylopyranosyl). 
antidiabetic and invigorating, aphrodisiac [28]. According to the traditional Congolese pharmacopoeia, the aqueous extract of the trunk bark of Panda oleosa would have similar properties [43] following tetracyclic triterpene saponins close to ginsenoside. The aphrodisiac property of saponins is related to their tetracyclic structure (see Figure 9).

Vernonia amygdalina also used in tradimedicine as antidiabetic and aphrodisiac contains tetracyclic triterpene saponosides called vernoniosides [43]. The invigorating property is very important for the diabetic who suffers from fatigue and erectile dysfunction due to diabetes complications [4].

\section{Acknowledgements}

Kombozi at Faculty of Sciences at the University of Kisangani and Dr Nestor Bebwa Baguma (Meise Botanic Garden, Belgium) are acknowledged for the herbarium identification of Panda oleosa. The Belgian Académie de Recherche et de l'Enseignement Supérieur (ARES) is also acknowledged for financial support to Njakarinala training.

\section{Conflict of Interest}

No conflict of interest.

\section{Ethical Issues}

The study was cleared by the University Research Ethical Committee.

\section{References}

[1] Le Gal, M. (2012) Les 6 processus physiopathologiques. De la situation clinique à la prise en charge du patient. [The 6 pathophysiological processes. From the clinical situation to the management of the patient.] Édition de boeck estem Paris, $581 \mathrm{p}$.

[2] Batina, A.S. (2015) Diabète sucré, maladies métaboliques et de nutrition. [Sweet Diabetes, Metabolic and Nutritional Diseases.] Presses de l'Université de Kisangani, R.D. Congo, $126 \mathrm{p}$.

[3] Ramon, C.G. (2009) Diabète. Traitements scientifiques et naturels. [Diabetes. Scientific and natural treatments.] Guide pratique de la santé. Édition Vidasana, Espagne, $142 \mathrm{p}$.

[4] Buysschaert, M. (2001) Diabétologie clinique. [Clinical Diabetology.] 2nd Edition, DE BOECK Université, 115-139, 151-317, 641-688.

[5] WHO. http://www.who.int/diabetes/en/

[6] PNLD or Programme National de Lutte contre le Diabète. [National Programme for the Control of Diabete.]

http://www.panapress.com/La-RDC-compte-pres-d-1-million-de-malades-du-diabe te,-selon-le-PNLD--13-784765-18-lang4-index.html

[7] American Diabetes Association (2014) Standards of Medical Care in Diabetes. Diabetes Care, 37, S14-S80.

[8] WHO Traditional Medicine Strategy 2014-2023. http://apps.who.int/iris/bitstream/10665/92455/1/9789241506090_eng.pdf?ua=1 
[9] International Regulatory Cooperation for Herbal Medicines (IRCH). http://www.who.int/medicines/areas/traditional/irch/en/

[10] Khan, M.H. and Yadava, P.S. (2010) Antidiabetic Plants Used in Thoubal District of Manipur, Northeast India. India Journal of Traditional Knowledge, 9, 510-514.

[11] Prasad, S.K., Kulshreshtha, A. and Qureshi, T.N. (2009) Antidiabetic Activity of Some Herbal Plants in Streptozotocin Induced Diabetic Albino Rats. Pakistan Journal of Nutrition, 8, 551-557. https://doi.org/10.3923/pjn.2009.551.557

[12] Patel, D.K., Prasad, S.K., Kumar, R. and Hemalatha, S. (2012) An Overview on Antidiabetic Medicinal Plants Having Insulin Mimetic Property. Asian Pacific Journal of Tropical Biomedicine, 2, 320-330.

[13] Spoor, D.C., Martineau, L.C., Leduc, C., Benhaddou-Andaloussi, A., Meddah, B. and Harris, C. (2006) Selected Plant Species from the Cree Pharmacopoeia of Northern Quebec Possess Antidiabetic Potential. Canadian Journal of Physiology and Pharmacology, 84, 847-858. https://doi.org/10.1139/Y06-018

[14] Antrade-Cetto, A. and Heinrich, M. (2005) Mexican Plants with Hypoglycemic Effect Used in the Treatment of Diabetes. Journal of Ethnopharmacology, 99, 325-348.

[15] Gbolade, A.A. (2009) Inventory of Antidiabetic Plants in Selected Districts of Lagos State, Nigeria. Journal of Ethnopharmacology, 121, 135-139.

[16] Atangwho, I.J., Edet, E.E., Uti, D.E., Obi, A.U., Asmawi, M.Z. and Ahmad, M. (2012) Biochemical and Histological Impact of Vernonia amygdalina Supplemented Diet in Obese Rats. Saudi Journal of Biological Sciences, 19, 385-392.

[17] Ong, K.W., Hsu, A., Song, L., Huang, D. and Tan, B.K.H. (2011) Polyphenols-Rich Vernonia amygdalina Shows Anti-Diabetic Effects in Streptozotocin-Induced Diabetic Rats. Journal of Ethnopharmacology, 133, 598-607.

[18] Ezike, A.C., Akah, P.A., Okoli, C.C. and Okpala, C.B. (2010) Experimental Evidence for the Antidiabetic Activity of Cajanus cajan Leaves in Rats. Journal of Basic and Clinical Pharmacy, 1, 81-84.

[19] Katemo, M., Mpiana, P.T., Mbala, B.M., Mihigo, S.O., Ngbolua, K.N., Tshibangu, D.S. and Koyange, P.R. (2012) Ethnopharmacological Survey of Plants Used against Diabetes in Kisangani City (DR Congo). Journal of Ethnopharmacology, 144, 39-43.

[20] Kasali, M.F., Mahano, A.O., Bwironde, F.M., Amani, A.C., Mangambu, J.D., Nyakabwa, D.S., Wimba, L.K., Tshibangu, D.S.T., Ngbolua, K.N., Kambale, J.K. and Mpiana, P.T. (2013) Ethnopharmacological Survey of Plants Used against Diabetes in Bukavu City (D.R. Congo). The Journal of Ethnobiology and Traditional Medicine, Photon, 119, 538-546.

[21] Kasali, M.F., Kadima, N.J., Mpiana, P.T., Ngbolua, J.P.K. and Tshibangu, D.S. (2013) Assessment of Antidiabetic Activity and Acute Toxicity of Leaf Extracts from Physalis peruviana (L.) in Guinea-Pig. Asian Pacific Journal of Tropical Biomedicine, 3, 885-890.

[22] Harris, D.J., Moutsambote, J.M. and Emile Kami, E. (2011) An Introduction to the Trees from the North Republic of Congo. Koeltz Scientific Books Publishers, Booksellers, Antiquarians in the Fields of Botany \& Zoology Koenigstein/Germany, 208.

[23] African Flowering Plants Database. http://www.villege.ch/musinfo/bd/cjb/Africa/recherché.php

[24] Bruneton, J. (2009) Pharmacognosie-Phytochimie, Plantes Médicinales. Lavoisier 4e éd, revue et augmentée, Tec \& Dac-Editions médicinales internationales, Paris, 1288 p. 
[25] Mabika, K. (1982) Plantes médicinales et médecine traditionnelle au Kasaï Occidental. [Medicinal Plants and Traditional Medicine in Western Kasai.] Thèse pour le doctorat de Botanique, Université nationale du Zaïre, Kisangani (inedit).

[26] Mharzi, I. and Zaid, A. (1995) Contribution à l'étude pharmacologique de Haloxylon scoparium. [Contribution to the Pharmacological Study of Haloxylon Scoparium (Chenopodiaceae).] Revue de Médecines et de Pharmacopées Africaines, 9, 159-167.

[27] Clément, D. (1969) Contribution à l'étude de la structure d'une saponine extraite d'une securidaceae Longipedunculata. [Contribution to the Study of the Structure of a Saponin Extracted from a Securidaceae Longipedunculata.] thèse inédite, Université de liège.

[28] EDQM (2016) Pharmacopée Européenne. [European Pharmacopoiea.] https://www.edqm.eu/fr

[29] FAO (1987). http://www.fao.org/search/fr

[30] EEC Directive (1986) Guide for the Care and Use of Laboratory Animals. http://eur-lex.europa.eu/legal-content/EN/TXT/PDF/?uri=CELEX:31986L0609\&fro $\mathrm{m}=\mathrm{EN}$

[31] Garcia, J., Massoma, T., Morin, C., Mpondo, N.T. and Nyassé, B. (1993) 4'-O-Methylgallocatechin from Panda oleosa. Phytochemistry, 32, 1626-1628.

[32] Ranasinghe, P., Perera, S., Gunatilake, M., Abeywardene, E., Gunapala, N., Premakumara, S., Perera, K., Lokuhetty, D. and Katulanda, P. (2012) Effects of Cinnamomum zeylanicum (Ceylon cinnamon) on Blood Glucose and Lipids in a Diabetic and Healthy Rat Model. Pharmacognosy Research, 4, 73-79.

https://doi.org/10.4103/0974-8490.94719

[33] Mateos-Martín, M.L., Fuguet, E., Quero, C., Pérez-Jiménez, J. and Torres, J.L. (2012) New Identification of Proanthocyanidins in Cinnamon (Cinnamomum zeylanicum L.) using MALDI-TOF/TOF Mass Spectrometry. Analytical and Bioanalytical Chemistry, 402, 1327-1336. https://doi.org/10.1007/s00216-011-5557-3

[34] Marcel, H.C. https://halshs.archives-ouvertes.fr/hal-00548850/document

[35] Protabase Plant Resources of Tropical Africa. https://www.prota4u.org/database/searchresults.asp

[36] Heidi, R., Bokesch, T.C., McKee, J.H.C. II and Boyd, M.R. (1993) Ent-4'-OMethylgallocatechin from Panda oleosa. Natural Product Letters, 44, 155-157. https://doi.org/10.1080/10575639408043898

[37] Okuda, T., Yoshida, T. and Hatano, T. (1992) Pharmacologically Active Tannins Isolated from Medicinal Plants. Basic Life Sciences, 59, 539-569.

[38] Babby, A., Elanchezhiyan, C., Suhasini, S. and Chandirasegaran, G. (2014) Antihyperglycemic Effect of Tannic Acid in Streptozotocin Induced Diabetic Rats. International Journal of Current Research, 6, 5396-5398.

[39] Chen, C.N., Lin, C.P., Huang, K.K., Chen, W.C., Hsieh, H.P., Liang, P.H. and Hsu, J.T. (2005) Inhibition of SARS-CoV 3C-Like Protease Activity by Theaflavin-3,30-Digallate (TF3). Evidence-Based Complementary and Alternative Medicine, 2, 209-215. https://doi.org/10.1093/ecam/neh081

[40] Arunachalam, K. and Parimelazhagan, T. (2013) Antidiabetic Activity of Ficus Amplissima Smith. Bark Extract in Streptozotocin Induced Diabetic Rats. Journal of Ethnopharmacology, 147, 302-310.

[41] Kunyanga, C.N., Imungi, J.K., Okoth, M., Momanyi, C., Biesalski, H.K. and Vadivel, V. (2011) Antioxidant and Antidiabetic Properties of Condensed Tannins in Ace- 
tonic Extract of Selected Raw and Processed Indigenous Food Ingredients from Kenya. Journal of Food Science, 76, C560-C567.

https://doi.org/10.1111/j.1750-3841.2011.02116.x

[42] Gauthier, C. (2008) Amélioration du comportement biopharmaceutique de triterpènes natureles anticancéreux par synthèse de saponines mono et bidesmosidiques. [Improvement of the Biopharmaceutical Behavior of Natural Anticoagulant Triterpenes by Synthesis of Mono and Bidesmosidic Saponins.] Thèse de doctorat en Sciences, Université du Québec, 332 p.

[43] Ministry of Public Health, Science and Tradition, DRC (2009) Pharmacopée Traditionnelle de la République démocratique du Congo. [Traditional Pharmacopoeia of the Democratic Republic of the Congo.] 1st Edition.

Submit or recommend next manuscript to SCIRP and we will provide best service for you:

Accepting pre-submission inquiries through Email, Facebook, LinkedIn, Twitter, etc. A wide selection of journals (inclusive of 9 subjects, more than 200 journals) Providing 24-hour high-quality service User-friendly online submission system Fair and swift peer-review system Efficient typesetting and proofreading procedure Display of the result of downloads and visits, as well as the number of cited articles Maximum dissemination of your research work

Submit your manuscript at: http://papersubmission.scirp.org/

Or contact ajac@scirp.org 